\title{
INFLUENCE OF GSD FOR 3D CITY MODELING AND VISUALIZATION FROM AERIAL IMAGERY
}

\author{
Muhamad Alrajhi, Zafare Alam, Mohammad Afroz Khan, Abdalla Alobeid
}

Dept. of Surveying and Mapping, Ministry of Municipal and Rural Affairs, Riyadh Olaya KSA alrajhi@momra.gov.sa, zalam@momra.gov.sa, afrozd.khan@gmail.com, alobeid@ipi.uni-hannover.de

\author{
Commission III, WG III/4
}

KEY WORDS: 3D City Modelling, DSM, Orthophoto, Oblique Imagery, Mesh Point, Wire Frame, Stereopairs, GSD

\begin{abstract}
:
Ministry of Municipal and Rural Affairs (MOMRA), aims to establish solid infrastructure required for 3D city modelling, for decision making to set a mark in urban development. MOMRA is responsible for the large scale mapping 1:1,000; 1:2,500; 1:10,000 and 1:20,000 scales for $10 \mathrm{~cm}, 20 \mathrm{~cm}$ and 40 GSD with Aerial Triangulation data. As 3D city models are increasingly used for the presentation exploration, and evaluation of urban and architectural designs. Visualization capabilities and animations support of upcoming 3D geo-information technologies empower architects, urban planners, and authorities to visualize and analyze urban and architectural designs in the context of the existing situation. To make use of this possibility, first of all 3D city model has to be created for which MOMRA uses the Aerial Triangulation data and aerial imagery. The main concise for 3D city modelling in the Kingdom of Saudi Arabia exists due to uneven surface and undulations. Thus real time 3D visualization and interactive exploration support planning processes by providing multiple stakeholders such as decision maker, architects, urban planners, authorities, citizens or investors with a three - dimensional model. Apart from advanced visualization, these 3D city models can be helpful for dealing with natural hazards and provide various possibilities to deal with exotic conditions by better and advanced viewing technological infrastructure. Riyadh on one side is $5700 \mathrm{~m}$ above sea level and on the other hand Abha city is $2300 \mathrm{~m}$, this uneven terrain represents a drastic change of surface in the Kingdom, for which 3D city models provide valuable solutions with all possible opportunities. In this research paper: influence of different GSD (Ground Sample Distance) aerial imagery with Aerial Triangulation is used for 3D visualization in different region of the Kingdom, to check which scale is more sophisticated for obtaining better results and is cost manageable, with GSD $(7.5 \mathrm{~cm}, 10 \mathrm{~cm}, 20 \mathrm{~cm}$ and $40 \mathrm{~cm})$. The comparison test is carried out in Bentley environment to check the best possible results obtained through operating different batch processes.
\end{abstract}

\section{INTRODUCTION}

3D city models are increasingly used for the presentation, exploration, and evaluation of urban and architectural designs (e.g., Döllner et al. 2006, Kibria et al. 2009, Song et al. 2009, Ross et al. 2009). Visualization capabilities and animation support of upcoming 3D geo-information technologies empower architects, urban planners, and authorities to visualize and analyse urban and architectural designs in the context of the existing situation. To make use of this possibility, first of all a 3D city model has to be created. In a second phase urban and architectural designs are added to the model. Real-time 3D visualization and interactive exploration of such models can support planning processes by providing multiple stakeholders such as decision-maker, architects, urban planners, authorities, citizens or investors with a three-dimensional model. It is argued that this method can help to identify design errors or conflicts of interest, to arbitrate conflicts, and for facilitating understanding. Moreover, it might offer a solution to make competing designs better comparable (Lange et al. 2004). In summary it is expected that the use of this technology can support communication and information processes, which will lead to more transparency in planning processes and also to better designs. An important factor which is seldom mentioned is that the use of 3D city models might help to save money and time. Large urban regeneration projects for example, often have a long planning history. Environmental damages, conflicting interests, a large diversity of stakeholders, legal requirements, political interests and many other issues are factors that have to be obeyed, moderated and finally lead to planning decisions. Thereby, it is very usual that plans are continuously changed, reworked and updated and often several physical models on different planning scales are created during the planning process. Digital 3D plan representations in conjunction with 3D city models might reduce costs and effort spent on preparing high quality presentations, map-print outs and physical models. The main aim of the project is to create a 3D city model of study area and its surrounding city districts, into which urban design proposals can be integrated. It is the first $3 \mathrm{D}$ city modelling project implemented on these 1:1,000; 1:2,500; $1: 10,000$ and 1:20,000 scales, therefore, further aims are to evaluate and develop workflows, test the capability of the software product and the applicability and usefulness of the technology in urban planning processes.

Digital 3D plan representations in conjunction with 3D city models might reduce costs and efforts spent on preparing high quality presentations, map print outs and physical models. 3D city models provide an intuitive media for the visualization and comparison of urban design proposals. With contemporary 3D city modelling methods 3D city models can be prepared in a level of detail sufficient for urban master planning as well as for detail studies and software solutions for the authoring, management and visualization of $3 \mathrm{D}$ city models.

To make use of this possibility, first of all 3D city model has to be created for which MOMRA uses the Aerial Triangulation data and aerial imagery. The main concise for 3D city modelling in the Kingdom of Saudi Arabia exists due to uneven surface and undulations. Thus real time 3D visualization and interactive exploration support planning processes by providing multiple stakeholders such as 
decision maker, architects, urban planners, authorities, citizens or investors with a three - dimensional model. Apart from advanced visualization, these 3D city models can be helpful for dealing with natural hazards and provide various possibilities to deal with exotic conditions by better and advanced viewing technological infrastructure. Riyadh on one side is $5700 \mathrm{~m}$ above sea level and on the other hand Abha is $2300 \mathrm{~m}$, this uneven terrain represents a drastic change of surface in the Kingdom, for which 3D city models provide valuable solutions with all possible opportunities.

\section{STUDY AREA}

Ad Dammam town lies in eastern Saudi Arabia, in Ash Sharqiyah (Al Hasa) Province, on the Persian Gulf. It is one of the nation's chief ports, serving as a major exporting point for petroleum and natural gas. Ad Dammam was a small coastal community until the late 1930 s, when it began to be developed as a port. Several large-scale residential and commercial building projects were undertaken here in the 1970s and early 1980s.

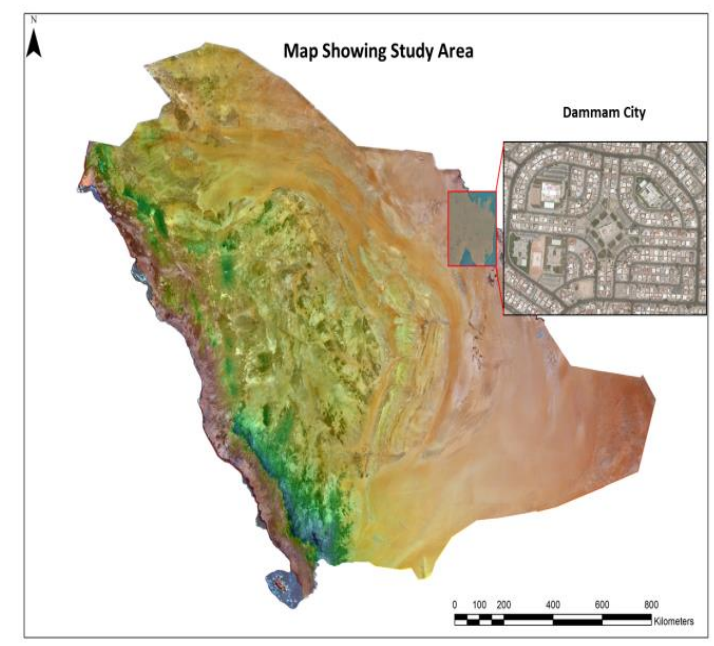

Figure 1. Showing study area of Dammam City

The port city is well connected by road, rail, and air with the rest of Saudi Arabia, as well as with its neighboring countries.

Apart from housing the main seat of the Easter Province administration, Dammam is a major residential and commercial center.

Dammam is about $400 \mathrm{~km}$ away from Riyadh. It is the capital of the Eastern region and a very important port. It was a separate small town but now it has become one big town, linking Al-Khobar and Al-Dhahran. Dammam is now a major commercial center.

Historians believe that Dammam was initially called DAMDAMA, which means the sound of drums that announce the beginning or the end of the hunting season. Near Dammam lies a very important center for refining petroleum. The population of Dammam is about one million.

Dammam retains the spirit of its past heritage, for which its local population is very proud. The Trading Port is reflective of a map of olden days. One well-maintained watch tower stands guard on King Saud Road as you pass from the City Center to Jubail highway. A typical conical structure, representing a glimpse of the past, is situated on the right corner of the bifurcating road leading to Saihat

\section{OBJECTIVES}

1. Study and creation of derived products from aerial imagery of achievable spatial accuracy and graphical quality of 3D city-model/Point-Cloud.

2. Comparison of level of details between 3D city model obtained from aerial and oblique imagery

3. Comparison of acquisition and processing duration of data for generation of 3D city model

\section{METHODOLOGY}

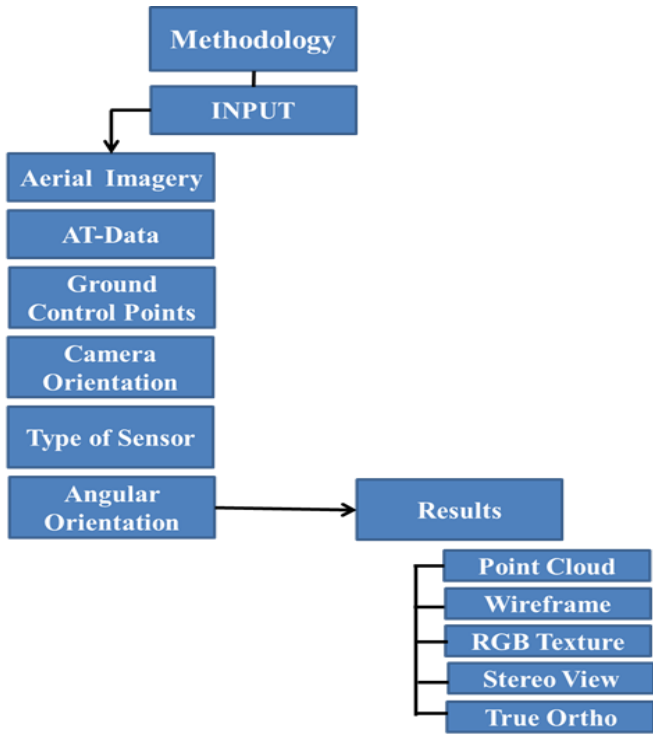

Figure 2. Methodology for creating 3D city models.

The current study was carried out for Ad Dammam City and designated to investigate influence of GSD (Ground Sample Distance) for 3D City modelling as shown in (Figure 2) and determine the quality of 3D city model based on the comparability of different GSD Aerial Imagery for decision and planning. To achieve the aforementioned objectives, the following methods were adopted: $(10 \mathrm{~cm}$ aerial imagery, Aerial Triangulation data, Ground control points, metadata) from Ministry of Municipal and Rural Affairs, (MOMRA), in this current study the Bentley Accute3DCity modzZ1234el with point cloud, wireframe, RGB texture, stereo view and true orthophoto.

\subsection{Aerial Imagery Data Source}

The aerial imagery data used for the study area is taken from MOMRA (Ministry of Municipal and Rural Affairs) at a height of 5500 meters; of scale 1:1,000 at a GSD of $10 \mathrm{~cm}$. also the data used for conducting this research includes oblique aerial photos with respective aerial triangulation data and metadata. 


\subsection{Derived Products}

The desired results obtained from executing various processes on aerial imagery of different GSD in Bentley environment to derive various outputs which includes:

The RBG texture image as in Figure 3 shows compatibility with natural look of the aerial imagery. The observed features can be interpreted and visualized in the image with all the ground surface features as in real view.

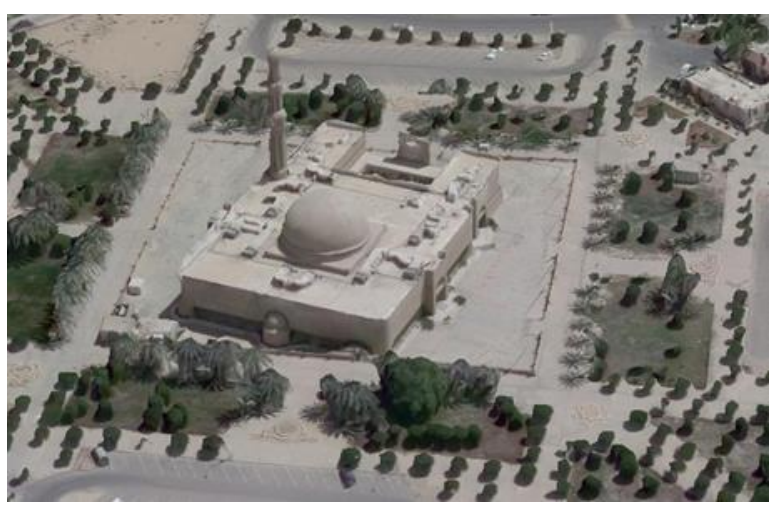

Figure 3.RGB texture from $10 \mathrm{~cm}$ Aerial Imagery.

The point cloud resulted from various image processes as shown in Figure 4.

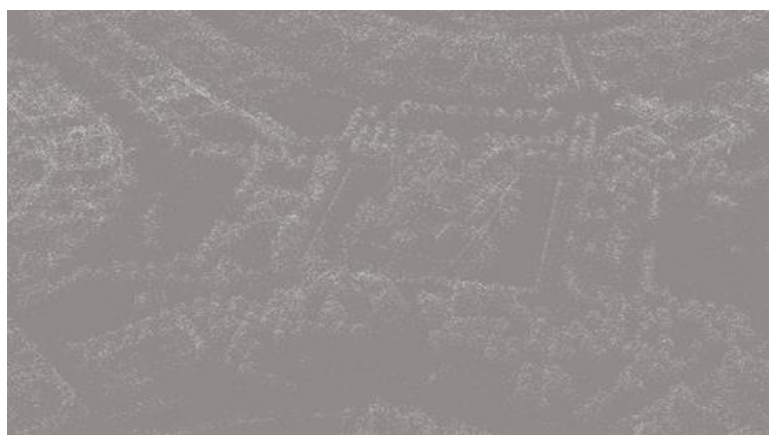

Figure 4. Point Cloud from 10cm Aerial Imagery.

The software provides us the capability to derive wireframe for the city of Dammam based on $10 \mathrm{~cm}$ GSD in a triangulated network as shown in Figure 5 below.

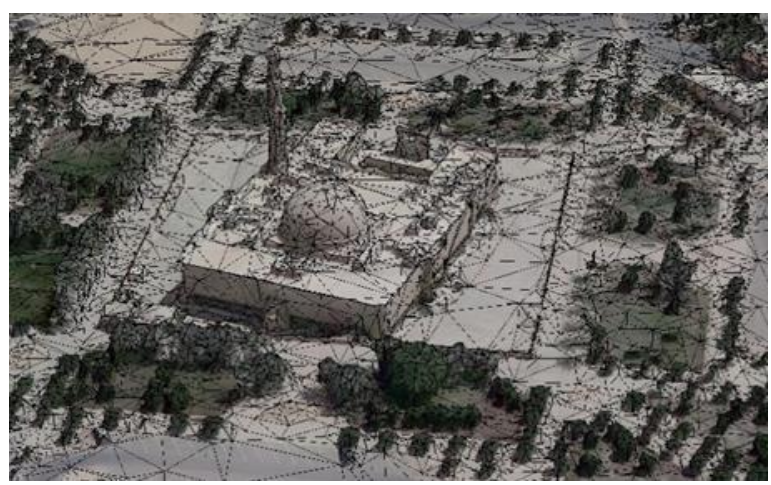

Figure 5. Wireframe from $10 \mathrm{~cm}$ Aerial Imagery.

The end product obtained from the Accu-3D provides Stereo view of the current study area as shown in Figure 6.

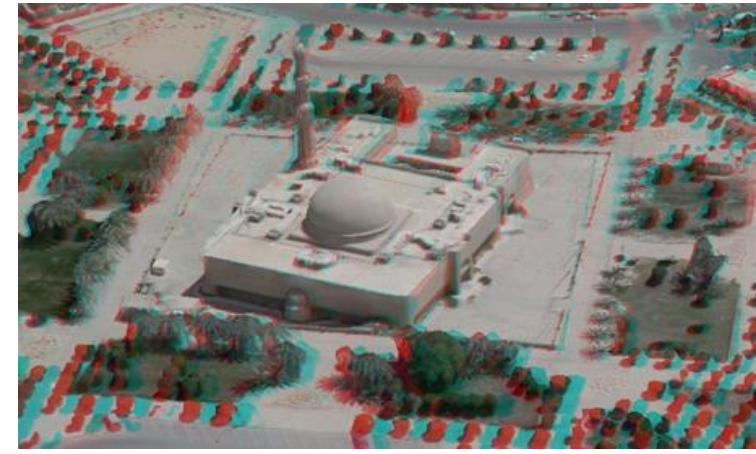

Figure 6. Stereo from $10 \mathrm{~cm}$ Aerial Imagery.

\section{CREATING 3D MODELS}

In this research paper the creation of $3 \mathrm{D}$ city model was carried out using aerial photos, oblique imagery with different GSD, in order to check the comparability of 3D models generated with respective aerial triangulation data with Context-Capture with (Acute3D-Bentley systems to Context Capture solution for reality modeling from photos 2015), comparing aerial Photogrammetry and 3D laser scanning methods for creating $3 \mathrm{~d}$ models of complex objects (Cyril Novel, Renaud Keriven; Philippe Graindorge; Florent Poux, 2004).

\subsection{D Reconstruction of Pictures Using Context- Capture}

The reconstruction of the traditional pictures into a 3D model was performed using Context Capture. The parameters for the aero triangulation process (for computing the orientation and position of the pictures) were set to the defaults, and the parameters for the 3D reconstruction were set to "Highest," the default preset. (Note that Context Capture also provides an "Ultra" preset mode, which allows for a denser reconstruction of the model, but it was determined to be inappropriate for this dataset.)

All 50 pictures were used for the reconstruction. The aero triangulation functionality of the software makes it possible to estimate the pixel resolution of the pictures - also called "Ground Sample Distance." In this case, the pixel resolution ranges from 10 centimeters, which means that a pixel in a picture is equal to roughly 1 centimeter.

The images were georeferenced using the seven remaining ground control points several weeks later than the original 18 points (based on the quality of the real-time kinematic [RTK] observation). The coordinates of the control points were computed by Geovast 3D.

The result of the photogrammetric processing was good; as shown in Figure 7, the model does not have holes, and there are no other obvious errors in the reconstruction of the Dammam city. 


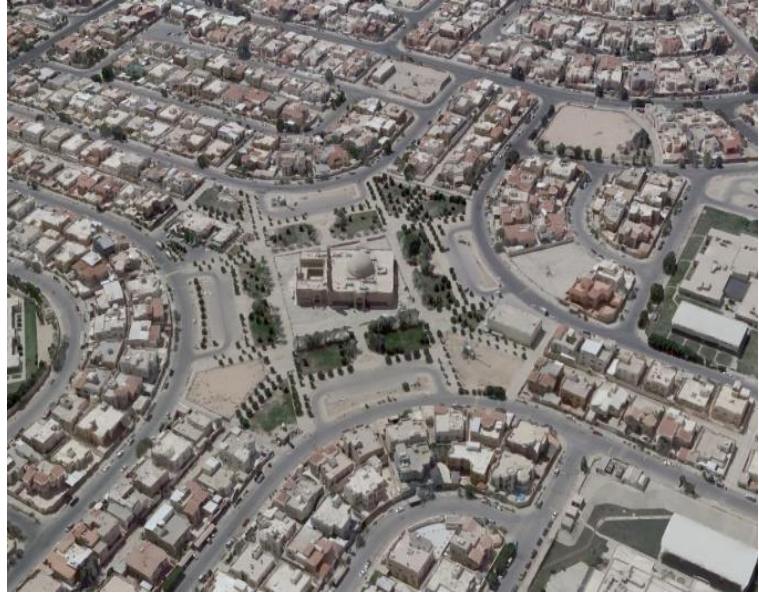

Figure 7. A 3D model of Dammam city.

\subsection{Comparison of Level of Details Between 3D City Model Obtained from Aerial and Oblique Imagery}

The results derived for 3D city model using aerial imagery and oblique imagery delineate drastic changes in the output results both in texture and shape of the features.

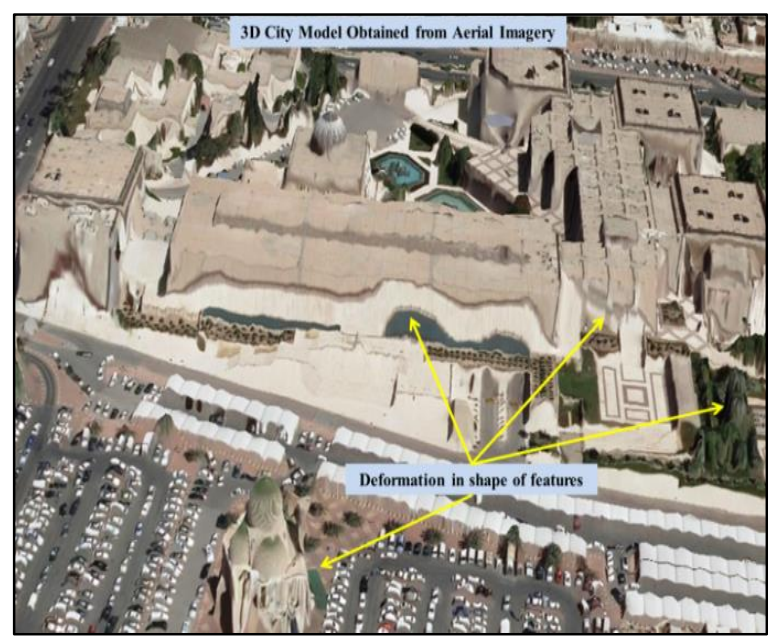

Figure 8. 3D texture obtained from aerial imagery (a).

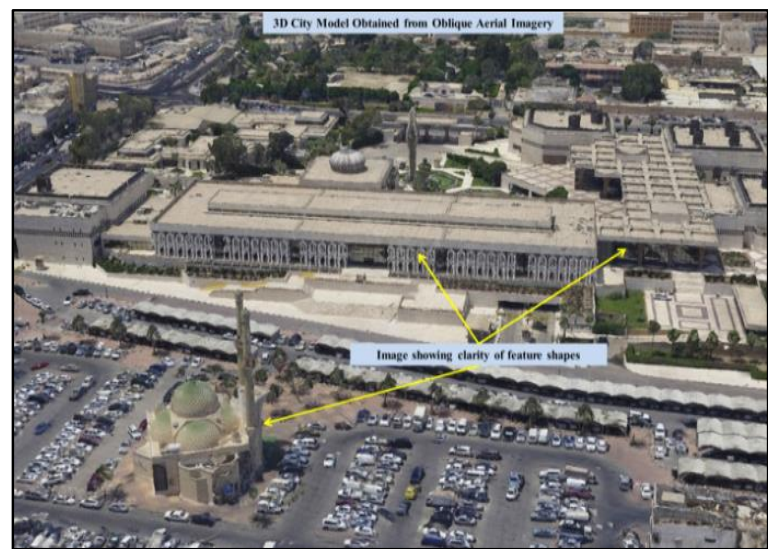

Figure 8. 3D texture obtained from oblique imagery (b).

The $3 \mathrm{D}$ city model results for aerial imagery delineates poor texture, deformed feature shapes in the output results because the overlap between the aerial images is $(80 / 60)$ percent forward overlap and (60/30) percent side overlap which is not sufficient to derive the better results. Due to which the resulted output image shows deformities among the features present in $3 \mathrm{D}$ city model as shown in Figure 8 . 3D texture obtained from aerial imagery (a).

While the 3D city model obtained from oblique colour imagery shows more clarity of features and minimal deformations among the features. Also the advantage of oblique imagery over aerial imagery is that it provides façade details also as shown in Figure 8. 3D texture obtained from oblique imagery (b).

No attempt was made to align the oblique imagery and aerial imagery, both of which were georeferenced in the MGD2000 reference coordinate system. Rather, the alignment was made using the control points.

Also it is important to note that the aerial imagery and oblique imagery were not captured at the same time. As a result, there are differences between the two data captures. For example, some objects have moved, and there is "noise". Also, many other objects like stationary cars, buildings had been moved, show deformation in outliers in the data due to the weather and various material properties. For these reasons, the comparison between the 3D model obtained from aerial imagery and Oblique imagery was made in same areas.

The higher resolution oblique imagery provides much better results than aerial imagery. Since the resolution of the oblique images is 1 centimeter per pixel, this is an excellent result, and we can extrapolate that if we had used much higher resolution imagery, the deviation between the two 3D models would be equivalent to just 2-3 pixels of the input photography.

Another factor to consider when comparing deviations between the two models is the distance of data capture devices from the city during data acquisition. Oblique imagery was taken from less height, whereas the aerial imagery was shot from 5500 feet in the air, looking down on the city. Thus, bottom of arches of the city cannot be captured from aerial imagery, as shown in Figure 8. 3D texture obtained from aerial imagery (a). If the photographers had walked around the city to capture ground-based photography, the photogrammetric model would have been equally complete.

\subsection{Comparison of acquisition and processing duration of data for generation of 3D city model.}

We also compared the time required to reconstruct Dammam city using aerial photos versus Oblique imagery:

- The total Oblique imagery processing takes six hours to complete.

- For aerial imagery, the flight time needed to acquire the pictures and production of 3D model required more time depending upon various atmospheric condition and factors. Therefore, total processing time taken for processing selected area of Dammam city to produce 3D model was eight hours and 30 minutes. 
This comparison indicates that oblique imagery enables faster production of $3 \mathrm{D}$ models and with less labor and expensive equipment required.

\section{RESULTS AND DISCUSSIONS}

When comparing 3D city models created from aerial imagery and oblique imagery, it has been interpreted that aerial imagery provides least sophisticated results for 3D modelling. While the oblique imagery produces more accurate reliable results. It requires less time and equipment.

Also oblique imagery allows for quicker data acquisition and easier processing because it has been taken from less height and the overlap of images is more than aerial imagery which is a major factor for generation of $3 \mathrm{D}$ city models with better interpretation results.

The generation of 3D city models is a major concern of municipalities for decision making and planning, thus MOMRA applies all possible methodologies to obtain better 3D city models with reliable accuracies and interpretation results for development of smart cities.

\section{AKNOWLEDGEMENT}

The authors would like to extend their sincere appreciation to the Ministry of Municipal and Rural Affairs of this research

\section{REFERENCES}

Autodesk (2009): Autodesk LandXplorer 2009. Online resource: http://www.landxplorer.com. Last accessed 26th March 2016.

Döllner, J., Kolbe, H.K., Liecke, F., Sgouros, T. \& Teichmann, K. (2006): The virtual 3D city model of Berlin managing, integrating and communicating complex urban information. 25th International Symposium on Urban Data Management UDMS, Aalborg, May, p. 15-17

Bulatov, D., Rottensteiner, F., Schulz, K. Context-based urban terrain reconstruction from images and videos. In Proceedings of the XXII ISPRS Congress of the International Society for Photogrammetry and Remote Sensing ISPRS Annals, Melbourne, Australia, 25 August-1 September 2012; p. 3 .

Kibria, M.S., Zlatanova, S., Itard, L., VanDorst, M.: GeoVEs as tools to communicate in urban projects: requirements for functionality and visualisation. In: Lee, Zlatanova (eds.) $3 D$ Geo-Information Sciences. LNG\&C, pp. 379-412. Springer, Heidelberg (2009)

Lange, E., Petschek, P. \& Stuppäck, S. (2004). Präsentation von Planungen. Der Einsatz von neuen Medien und 3DVisualisierungen beim Wettbewerb ZürichLeutschenbach. Stadt + Grün, 7, pp. 22-26.

Wang, Y. 3D GIS Spatial Modelling for City Surface and Subsurface Integration, published by IEEE, 2006, pp. 1511 1518 .

Zlatanova, S., Abdul Rahman, A. \& Pilouk, M “3D GIS: Current Status and Perspectives" ISPRS Commission IV, WGIV/1, 2002, pp. 1-6.
Zlatanova, S., (2008). Acquisition-Position Paper-Data Collection and $3 D$ reconstructionand, Advances in $3 D$ Geoinformation Systems, van Oosterom, P., Zlatanova, S., Penninga, F., \& Fendel, E., (eds). published by Springer Berlin-Heidelberg, New York, pp. 425-428. 